\title{
DECOMPOSITION OF THE ZENGA INEQUALITY INDEX I(Y) INTO THE CONTRIBUTIONS OF MACROREGIONS AND INCOME COMPONENTS - AN APPLICATION TO DATA FROM POLAND AND ITALY
}

The total income $Y$ can be expressed as the sum of $c$ components called income sources. The $N$ units of the population can be partitioned into $k$ different subpopulations. In the paper the decompositions by subpopulations as well as by income components of the point $I_{h}(Y)$ and the synthetic $I(Y)$ inequality indexes proposed by Zenga in 2007 are considered. These indexes can be decomposed into the contributions of income sources and/or into the contributions of subpopulations , and also the decomposition into within- and between-group inequality can be carried out. In the paper, the two-step approach was used: first of all "additive" decompositions of the point index were derived, and then, by averaging these decompositions, the corresponding decompositions of the synthetic index were obtained. The results were then applied to the analysis of income distributions in Poland and Italy based on the household budget surveys conducted by Statistics Poland and the Bank of Italy, respectively.

Keywords: income inequality, decomposition by factor components, decomposition by subpopulations

DOI: $10.15611 /$ aoe.2020.1.05

\section{INTRODUCTION}

The pursuit of "economic, social and territorial cohesion" through closer regional and national harmonisation was proclaimed in the 2007 Lisbon Treaty, but deepening European integration has not always been matched with a convergence in living standards between sub-national regions. The gap between poorer and richer areas increased during the last economic crisis even in some developed economies, and the income discrepancy between richer and poorer regions is likely to widen further as governmentspending cuts disproportionately hurt less prosperous regions. The evidence

\footnotetext{
* Department of Statistics and Quantitative Methods, University of Milan-Bicocca.

** Department of Statistical Methods, University of Lodz.
} 
on income inequality and poverty collected for OECD countries confirms that there has been a significant increase in income inequality, which has grown since at least the mid-1980 and there are still substantial differences in regional income levels (see: Growing Unequal?, OECD 2008; Divided We Stand. Why Inequality Keeps Rising, OECD 2011, In It Together: Why Less Inequality Benefits All, OECD 2015). The problems of growing income and wealth inequalities in the modern world, supplemented by an in-depth statistical analysis of this phenomenon in the long-term perspective, were recently discussed in Piketty (2014).

This growing disparity calls for the analysis of various aspects of income inequality, including its measurement and decompositions by regional areas and by income sources. For the purpose of putting this into practice of social and economic policies, it seems interesting to compare income inequality across EU countries and regions. According to household budget surveys conducted in Poland and Italy in 2014, the popular Gini indexes for net household incomes were rather high and equalled 0.34 and 0.35 , respectively. In this context, it would be especially interesting to compare and contrast inequality decomposition in Poland and Italy, the countries with similar levels of overall income inequality but with different historic, geographic and socio-economic characteristics. Did the process of growing inequalities over the last few decades affect both these countries uniformly? What are the contributions of particular macroregions to the overall inequality? What can be concluded about the discrepancies between and within regions? What are the contributions of basic income components to the overall income inequality in Poland and Italy?

The answers to these questions can help with better understanding of the complicated relationship between income inequality and economic growth, which has been for decades the subject of many economic studies. In particular, the main question concerned the existence and the evidence of the relation between these two socio-economic phenomena (see e.g. Persson and Tabellini, 1994).These relationships were also discussed in Sztaudynger and Kumor (2007), where the authors tried to look for the level of income inequality which is optimal from the point of view of economic growth and social welfare in Poland.

Observing different inequality patterns in Poland and Italy one can also compare and contrast overall and regional income inequalities in a 'transition' economy and a well-established market economy. According to the Tárki European Social Report from 2009, a study on the intolerance to income inequality across countries confirmed the markedly lower level of 
acceptance of inequality in the post-socialist bloc than in other European countries. Nonetheless, income inequality in Poland increased significantly during the process of transformation from a centrally-planned to a market economy: e.g. the Gini index went up by approximately 10 percentage points. After the period of rapid economic changes, the rate of growth of the Gini index in Poland slowed down and now one can observe only slight fluctuations at about the level 0.34-0.35 according to the Household Budget Survey (HBS) data, and about 0.31 according to EU-SILC (in the latter survey the equivalised income is considered). In Italy, after the post-war boom accompanied by extremely high income inequality, there was a clear decline in the income inequalities at the end of the 1970s (the Gini index decreased from the level of 0.39 in 1979 to 0.33 in 1990). In contrast, ten years later the Gini index visibly rose and in 1995 exceeded 0.36.The decline corresponded with a period of economic expansion characterised by liberal policies, whereas the rapid increase coincided with the striking economic crisis. After 2008, the initial year of the current financial crisis, inequality in Italy slightly increased again to 0.35 in terms of the value of the Gini coefficient (Jędrzejczak, 2015a).

Since the times of Pareto, that is from the beginning of the formal statistical analysis of income size distributions, numerous inequality measures have been proposed, including the classical and still the most popular Gini, Bonferroni, Theil and Atkinson coefficients. More recently an interesting inequality measure based on the relation between income and distribution quantiles was developed by Zenga $(1984,1990)$, and since then it has become increasingly popular in the economic literature; see e.g. Jędrzejczak (2015b), Arcagni (2017). In 2007 Zenga proposed another inequality measure based on lower and upper mean, which seems to overtake the former one due to its simplicity and straightforward economic interpretation (Zenga, 2007). What is more, both the above-mentioned synthetic inequality measures proposed by Zenga were obtained as simple or weighted arithmetic means of their corresponding point inequality measures (concentration curves). Their underlying concentration curves do not present the so-called "forced" or pre-established behaviour, as do the Lorenz and the Bonferroni curves, so they are sensitive to changes of income inequality at every part of income distribution. Moreover, the Zenga (2007) index is based on comparisons of the means of less and more fortunate sub-populations, irrespectively of the threshold that might be used to delineate the two groups. In Zenga (2007) it was shown that the Bonferroni and the Gini-Lorenz curves have a forced behaviour, and it was also shown that the Zenga (2007) 
index satisfies the properties usually required to a synthetic inequality measure. In particular, scale invariance axiom, symmetry axiom, transfer axiom and additive decomposability were considered. On this point see also: Zenga (1990) and Arcagni and Porro (2014). Statistical inference for the Zenga (2007) index was studied in Langel and Tillé (2012), where an inferential procedure based on linearization was developed and compared with the procedures for the Gini index. Greselin et al. $(2010,2013)$ also discussed the "new" Zenga index properties, including the two-sample inferential issues, and obtained confidence intervals for the difference of the Zenga indices between 2006 and 2004 in the Italian income distribution.

A very important characteristic of an inequality measure is its suitability for the decompositions by subpopulations and income sources; see: Rao (1969), Pyatt (1976), Shorrocks (1980), Lerman and Yitzhaki (1985), Tarsitano (1990), Dagum (1997a, 1997b), Radaelli and Zenga (2005), Monti (2008). The aim of the above-mentioned publications was the decomposition (by sources, by subpopulations) of the synthetic inequality indexes of Gini, Bonferroni, Herfindahl, and Theil. Special attention was paid to the definition of the class of "additively decomposable inequality measures" and to overcoming the difficulties with the group decomposition of the Gini index. It is worth noting that in the case of the Zenga (2007) index the approaches proposed for the decompositions by subpopulations (Radaelli, 2008, 2010; Zenga, 2016a) and by sources (Zenga et al., 2012), are such that they obtain, first of all "additive" decompositions of the point index $I_{h}(Y)$, and then, by averaging these decompositions, they obtain the corresponding decompositions of the synthetic index $I(Y)$. Following this two-step approach, Zenga (2013) decomposed by sources the Gini and the Bonferroni point and synthetic indexes; in this paper is also shown that the contribution of the sources $X_{j}$ to the synthetic Gini index obtained with the two-step approach is equal to the ones obtained by Rao (1969), Lerman and Yitzhaki (1985), and by Radaelli and Zenga (2005). Unfortunately, these latter decompositions cannot give information on the contributions of $X_{j}$ to the Gini point index. This happens because these decompositions are based on the following expression of the synthetic Gini index: $G(Y)=\Delta(Y) /[2 M(Y)]$, where $\Delta(Y)$ is the Gini mean difference. Very recently, Pasquazzi and Zenga (2018) applied the above-mentioned new (two-step) approach for the decomposition by sources of the Gini (1914), Bonferroni (1930) and Zenga (2007) inequality indexes to income data from the 2001 wave of the 
European Community Household Panel (ECHP). Recently, using the twostep approach Zenga and Valli (2016) decomposed by subpopulations the point and the synthetic Bonferroni inequality measures, while Zenga (2016b) decomposed the point and the synthetic Gini indexes. Finally, the two-step approach was utilized for the decompositions by sources and by subpopulations of the Zenga (1984) inequality index, too. For details on these latter decompositions see Arcagni and Zenga (2014) and Arcagni (2017) for the decomposition by sources, and Porro and Zenga (2014) for the decomposition by subpopulations. Various decompositions of the Gini index with the application to the Polish data were discussed in Jęrzejczak (2010).

One notes that in the case of the above-mentioned decompositions by subpopulations, obtained by the use of the two-step approaches, one can obtain both the inequality decomposition into the contributions of particular groups of income receivers and the inequality decomposition into within and between group parts.

The aim of this paper is to present the new (two-step) convenient method for income inequality decomposition by subpopulations and by sources of income. In particular, the contributions from macro regions and from income components to the Zenga (2007) point and overall inequality measures were considered. These decompositions can be used to answer the questions mentioned above. The application is based on the micro data coming from the Polish Household Budget Survey and the Italian Sample Survey on Household Income and Wealth.

\section{DEFINITIONS AND NOTATION}

Let $X_{1}, \ldots, X_{j}, \ldots, X_{c}$ be $c$ variates (income sources) observable on each of the $N$ units of the population, and $Y=\sum_{j=1}^{c} X_{j}$ be the total income. Let $\left\{0 \leq y_{1}<\ldots<y_{h}<\ldots<y_{r}\right\}$ be the set of the distinct values assumed by the variate $Y$ and $\left\{n_{1}, \ldots, n_{h}, \ldots, n_{r}.\right\}$ be the corresponding frequencies: $\sum_{h=1}^{r} n_{h .}=N$. At each $y_{h}$ the whole population can be split into two nonoverlapping groups: a lower group with $\left\{Y \leq y_{h}\right\}$, and the corresponding upper group with $\left\{Y>y_{h}\right\}$.

Let $\bar{M}_{h .}(Y)$ and $\stackrel{+}{M}_{h}(Y)$ be: the arithmetic mean (lower mean) of the lower group and the arithmetic mean (upper mean) of the upper group, 
respectively. The Zenga (2007) point $I_{h}(Y)$ and synthetic $I(Y)$ indexes are given by:

$$
I_{h}(Y)=\frac{\stackrel{+}{M}_{h .}-\bar{M}_{h .}}{\stackrel{+}{M}_{h .}} \text { and } I(Y)=\sum_{h=1}^{r} I_{h}(Y) \frac{n_{h .}}{N} .
$$

Notice that $I_{h}(Y)$ is the relative variation of $\bar{M}_{h}(Y)$ w.r.t. $\stackrel{+}{M}_{h}(Y)$.

It can easily be noticed that the synthetic index $I(Y)$ is the weighted arithmetic mean of the point measures $I_{h}(Y)$ with the weights established as the relative frequencies of the distinct values of income in the population.

This paper also considers the bivariate distribution of the $N$ units according to $k$ different subpopulations and the $r$ distinct values of $Y$. In this distribution $n_{h g}$ is the frequency of the value $y_{h}$ in the subpopulation $g$; $n_{h . .}=\sum_{g=1}^{k} n_{h g} ; n_{. g}=\sum_{h=1}^{r} n_{h g}$ is the size of subpopulation $g ; N=\sum_{g=1}^{k} n_{. g}$. $\bar{M}_{h g}(Y)$ and $\stackrel{+}{M}_{h g}(Y)$ are, respectively, the lower mean and the upper mean of the distribution $\left\{\left(y_{h}, n_{h g}\right): h=1, \ldots, r\right\}$ of the subpopulation $g$. The authors also consider the point $I_{h g}(Y)$ and the synthetic $I_{. g}(Y)$ indexes of subpopulation $g$ that are given by:

$$
I_{h g}(Y)=\frac{\stackrel{+}{M}_{h g}-\bar{M}_{h g}}{\stackrel{+}{M}_{h g}} \text { and } I_{\cdot g}(Y)=\sum_{h=1}^{r} I_{h g}(Y) \frac{n_{h g}}{n_{g}} .
$$

The curves of $I_{h}(Y)$, evaluated on several income distributions, are U-shaped (see: Zenga, 2007; Zenga et al., 2012). Polisicchio (2008) has shown that only the truncated Pareto distribution with lower limit $\mu \times k$, upper limit $\mu / k$ and inequality parameter $\theta=0.5$ has a constant point inequality index equal to $(1-k): 0<k<1$ and $\mu>0$. Moreover, Polisicchio and Porro (2011) compared the Zenga and Lorenz curves and studied their behaviour for many continuous random variables. Additionally, Maffenini and Polisicchio (2014) compared the Zenga and Lorenz curves in the case of translations and equalitarian transfers. 


\subsection{Decomposition by subpopulations}

Radaelli (2010) decomposed the Zenga index by $k$ subpopulations starting with the decomposition of the point uniformity measure $U_{h}=1-I_{h}$. Zenga (2016a, sec.3) decomposed his index in a more direct way starting with the following basic $k \times k$ additive decomposition of the point inequality index $I_{h}(Y)$ :

$$
I_{h}(Y)=\sum_{l=1}^{k} \sum_{g=1}^{k} B_{h l g}(Y),
$$

where $B_{h l g}(Y)=\left(\left(\stackrel{+}{M}_{h g}-\bar{M}_{h l}\right) / \stackrel{+}{M}_{h .}\right) \cdot p(l \mid h) \cdot a(g \mid h)$ is the contribution to the point index $I_{h}(Y)$ that derives from the comparison of $\bar{M}_{h l}(Y)$ and $\stackrel{+}{M}_{h g}(Y)$ i.e. the lower and upper means coming from two subpopulations $l$ and $g$, respectively. It is important to point out that the contributions $B_{h l g}(Y)$ cannot take negative values.

It comes from formula (3) that the point inequality $I_{h}(Y)$ is a weighted mean of $k \times k$ relative differences between all possible ordered pairs of subpopulations, taking the upper mean of the subpopulation $g$ and the corresponding lower mean of the subpopulation $l$. The weights, which play an important role in this decomposition, are the products of the relative frequencies $p(l \mid h)$ and $a(g \mid h)$ where $p(l \mid h)$ is the relative frequency of subpopulation $l$ in the lower group and $a(g \mid h)$ is the relative frequency of subpopulation $g$ in the upper group.

The $k \times k$ decomposition by subpopulations of the synthetic index $I(Y)$ can be obtained by means of the aggregation of the previous formula for distinct values of income and is given by:

$$
I(Y)=\sum_{h=1}^{r}\left\{\sum_{l=1}^{k} \sum_{g=1}^{k} B_{h l g}(Y)\right\} \frac{n_{h .}}{N}=\sum_{l=1}^{k} \sum_{g=1}^{k} B_{. l g}(Y)
$$

where $B_{\text {lg }}(Y)=\sum_{h=1}^{r} B_{h l g}(Y) \frac{n_{h .}}{N}$.

Through different aggregations of the contributions $B_{h l g}(Y)$, many other additive decompositions of $I_{h}(Y)$ are derived. In particular, the inequality 
index can be decomposed into the contributions of the $k$ considered subpopulations:

$$
I_{h}(Y)=\sum_{l=1}^{k} B_{h l}(Y)
$$

where $B_{h l .}(Y)=\sum_{g=1}^{k} B_{h l g}(Y)=\left[\frac{\stackrel{+}{M}_{h .}(Y)-\bar{M}_{h l}(Y)}{\stackrel{+}{M}_{h .}(Y)}\right] p(l \mid h)$ is the contribution of subpopulation $l$ to the point index $I_{h}(Y)$. Notice that $\left(\stackrel{+}{M}_{h .}(Y)-\bar{M}_{h l}(Y)\right) / \stackrel{+}{M}_{h .}(Y)$ is the relative variation of $\bar{M}_{h l}(Y)$ w.r.t. $\stackrel{+}{M}_{h}(Y)$. Now, in the same way, the synthetic index $I(Y)$ is decomposed as follows:

$$
I(Y)=\sum_{l=1}^{k}\left\{B_{. l l}(Y)+\sum_{g: g \neq l} B_{. l g}(Y)\right\}=\sum_{l=1}^{k} B_{l l}(Y)
$$

where $B_{l .}(Y)=\sum_{g=1}^{k} B_{. l g}(Y)$ is the contribution of subpopulation $l$ to $I(Y)$.

Finally, the point index $I_{h}(Y)$, and then the synthetic index $I(Y)$, can be split into the within and the between components:

$$
I(Y)=B_{. . w}(Y)+B_{. . B}(Y) .
$$

To obtain the within inequality, the diagonal elements of the matrix consisting of the elements $B_{h l g}(Y)$ are added up; by adding up the offdiagonal elements the between inequality can be obtained:

$$
\begin{gathered}
B_{. . W}(Y)=\sum_{l=1}^{k}\left\{\sum_{h=1}^{r}\left[\frac{\stackrel{+}{M}_{h l}(Y)-\bar{M}_{h l}(Y)}{\dot{+}_{h .}(Y)}\right] p(l \mid h) \cdot a(l \mid h) \cdot \frac{n_{h .}}{N}\right\}, \text { and } \\
B_{. . B}(Y)=\sum_{l=1}^{k} \sum_{(g: g \neq l)}\left\{\sum_{h=1}^{r}\left[\frac{\stackrel{+}{M}_{h g}(Y)-\bar{M}_{h l}(Y)}{\stackrel{+}{M}_{h .}(Y)}\right] p(l \mid h) \cdot a(g \mid h) \cdot \frac{n_{h .}}{N}\right\} .
\end{gathered}
$$

The within-groups component derives from the comparison of the lower mean and the upper mean of the same subpopulation while the other 
component involves the means coming from different ones. Note that the within component is given by the sum of $k$ terms and the between component is the sum of $k \times(k-1)$ components.

\subsection{Decomposition by income sources}

The contribution of the income sources $X_{j}$ to the total income inequality index can also be obtained (Zenga et al. 2012) by the use of a two-step approach. In the first step, additive decompositions of the point measure $I_{h}(Y)$ are derived. In the second step, the corresponding decompositions of the synthetic measure $I(Y)$ are easily derived by putting the point decompositions into the formula of the weighted arithmetic mean (see equation 1).

Let $\bar{M}_{h .}\left(X_{j}\right)$ and $\stackrel{+}{M}_{h}\left(X_{j}\right)$ be the means of $X_{j}$ in the lower group and in the upper group, respectively. Zenga et al. (2012) obtained the following additive decompositions by sources of the point $I_{h}(Y)$ and the synthetic $I(Y)$ inequality measures:

$$
I_{h}(Y)=\sum_{j=1}^{c} B_{h}\left(X_{j}\right), \quad I(Y)=\sum_{j=1}^{c} B\left(X_{j}\right),
$$

where: $B_{h}\left(X_{j}\right)=\frac{1}{\stackrel{+}{M}_{h .}(Y)}\left(\stackrel{+}{M}_{h .}\left(X_{j}\right)-\bar{M}_{h .}\left(X_{j}\right)\right)$ is the contribution of $X_{j}$ to $I_{h}(Y)$ and $B\left(X_{j}\right)=\sum_{h=1}^{r} B_{h}\left(X_{j}\right) \cdot \frac{n_{h .}}{N}$ is the contribution of $X_{j}$ to $I(Y)$. The component $B_{h}\left(X_{j}\right)$ is the relative difference between the upper and the lower means of the component $X_{j}$ related to the upper mean of the total income $Y$.

It can also be interesting to evaluate the relative contributions of particular income components to the Zenga point $I_{h}$ and synthetic $I$ inequality measures. These contributions can further be compared to the corresponding contributions of income sources to the total mass of income. If $I_{h}>0$, one may define the relative contribution of $X_{j}$ to $I_{h}$ by:

$$
\beta_{h}\left(X_{j}\right)=\frac{B_{h}\left(X_{j}\right)}{I_{h}}=\frac{\stackrel{+}{M}_{h}\left(X_{j}\right)-\bar{M}_{h}\left(X_{j}\right)}{\stackrel{+}{M}_{h}-\bar{M}_{h}} .
$$


Let us suppose that $\beta_{h}\left(X_{j}\right)=0.3$, which means that the difference between the upper and the lower mean of the income source $X_{j}$ is $30 \%$ of the difference between the respective means of total income $Y$ at the point $h$. The contributions of particular income sources to the overall income inequality $I$ can be assessed by averaging (10) over all distinct values of income.

A similar approach can be applied within each subpopulation $g$ $(g=1, \ldots, k)$. In particular, the decompositions by sources of the point $I_{h g}(Y)$ and the synthetic $I_{. g}(Y)$ inequality indexes are given by:

$$
I_{h g}(Y)=\sum_{j=1}^{c} B_{h g}\left(X_{j}\right) \quad \text { and } \quad I_{. g}(Y)=\sum_{j=1}^{c} B_{. g}\left(X_{j}\right)
$$

where: $B_{h g}\left(X_{j}\right)=\left(\stackrel{+}{M}_{h g}\left(X_{j}\right)-\bar{M}_{h g}\left(X_{j}\right)\right) / \stackrel{+}{M}_{h g}(Y)$ is the contribution of $X_{j}$ to $I_{h g}(Y), B_{\cdot g}\left(X_{j}\right)=\sum_{h=1}^{r} B_{h g}\left(X_{j}\right) \cdot \frac{n_{h g}}{n_{\cdot g}}$ is the contribution of $X_{j}$ to $I_{. g}(Y)$.

The last term can be interpreted as the arithmetic mean of the contributions of $X_{j}$ to the point indexes $I_{h g}(Y)$.

Recently, Zenga (2013) used the above two-step approach for the decomposition by sources of the Gini (1914) and the Bonferroni (1930) indexes. This unified approach made it possible to find out that the relative contributions of income sources $X_{j}$ to the three point indexes: Zenga, Gini and Bonferroni are equal. Therefore the respective relative contributions to the Zenga, Gini and Bonferroni synthetic inequality measures are weighted arithmetic means of point measures contributions with different weights.

\section{APPLICATION}

The proposed methods of inequality decomposition, by subpopulations and by sources of income, were applied to the analysis of income distributions in Poland and Italy. For both countries the samples of households were divided into the following subpopulations (equivalent to NUTS1, according to Eurostat classification): 
- Poland - six macro regions: 1. Central, 2. Southern, 3. Eastern, 4. NorthWestern, 5. South-Western, 6. Northern

- Italy - three macro regions: 1. North, 2. Center, 3. South.

This paper deals with the household net disposable income Y, defined as the sum of the following components (sources of income):

- X1 - payroll income,

- $\mathrm{X} 2$ - pensions and net transfers,

- X3 - net self-employment income,

- X4 - property incomes.

The basis for the calculations was individual data from the year 2014 obtained from the Household Budgets Survey (HBS) conducted by Statistics Poland (formerly the Central Statistical Office), and the sample Survey on Household Income and Wealth (SHIW) conducted by the Bank of Italy. The data obtained from both surveys allow for the analysis of the living conditions of households, being the basic sources of information on the revenues and expenditure of the populations of Poland and Italy. Both random samples were selected by means of two-stage stratified sampling designs with unequal inclusion probabilities for primary sampling units. In order to maintain the relation between the structure of the surveyed population and the socio-demographic structure of the total population, the data obtained from the Polish HBS were weighted with the structure of households by the number of persons and the class of locality coming from the Population and Housing Census 2011. In 2014 the Polish sample covered 37,216 households, i.e. approximately $0.3 \%$ of the total number of households while the Italian sample covered 8,156 households $(0.03 \%$ of all). All the computations that follow consider the weights established on the basis of the inverse of the household's probability of inclusion in each sample and the relevant ex-post adjustment. For more details see Statistics Poland (2015), the Bank of Italy (2016).

In Tables 1 and 2 there are statistical characteristics of both samples for all the variables of interest: $\mathrm{Y}, \mathrm{X} 1, \mathrm{X} 2, \mathrm{X} 3, \mathrm{X} 4$, calculated for macroregions as well as for whole countries. It can be noticed that in Italy (Table 1) the Northern region overwhelms the others in terms of the share of its households in the overall sample size (45\%) and even more in terms of the share of their income (51\%). In Poland, the corresponding shares of particular regions are more balanced with the domination of the largest and most affluent Central one. In addition, income structures in both countries differ a lot: in Poland the payroll income constitutes $53 \%$ of the disposable income with the negligible role of property income $(0.3 \%)$ which is in turn meaningful in Italy $(22 \%)$. The graphical representations of the Polish and Italian data are given in Figure 1. 


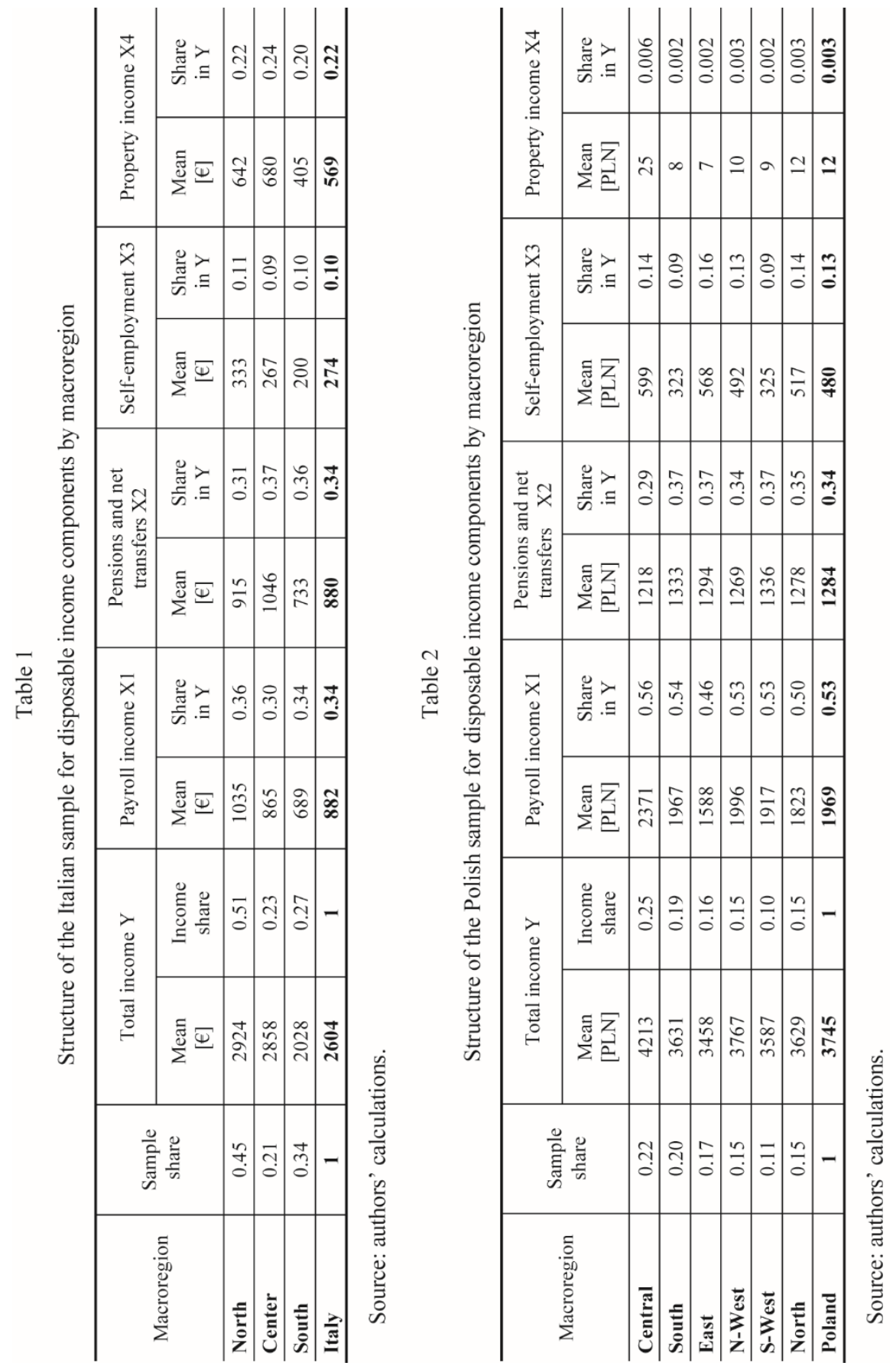




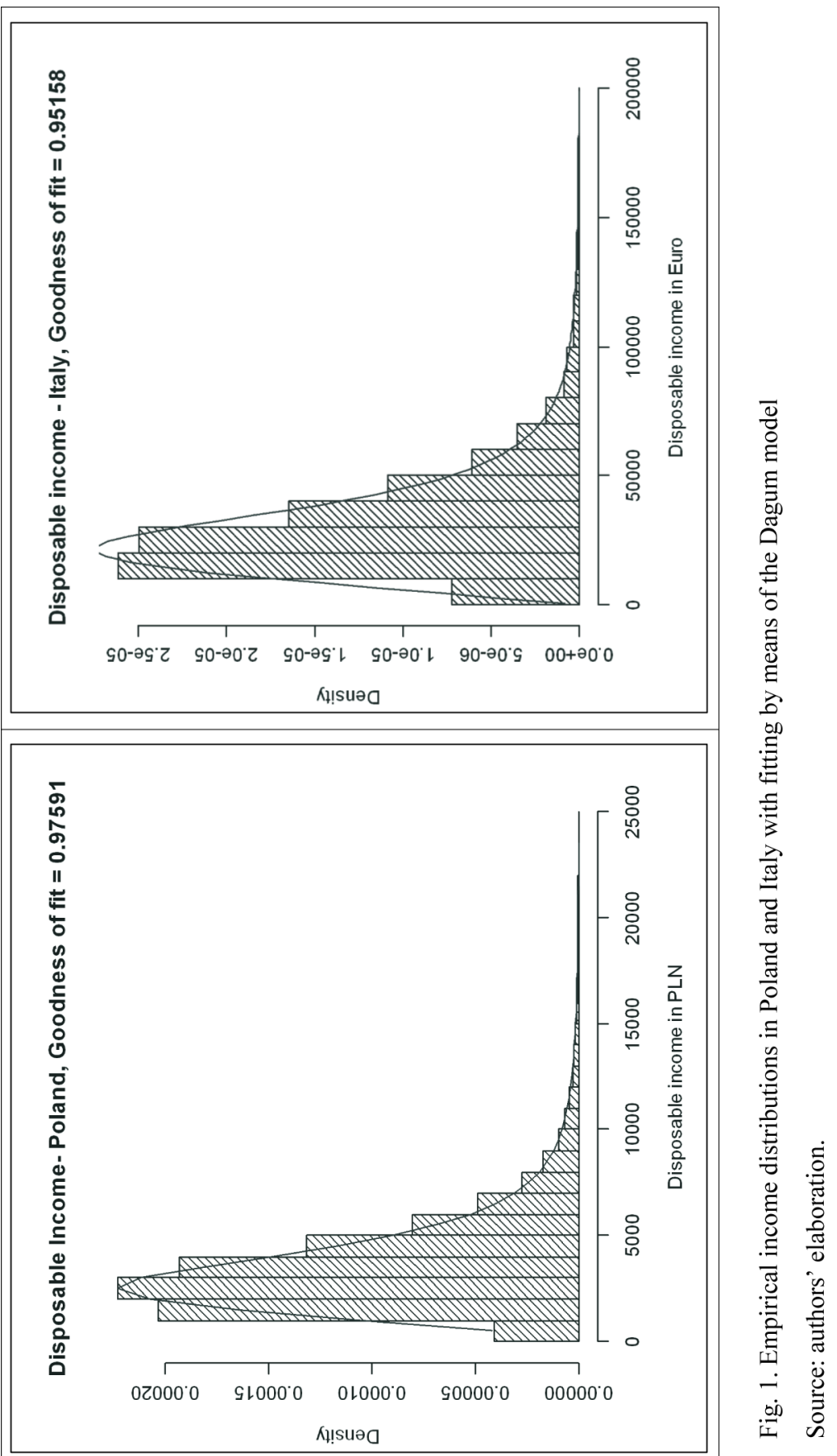


The histograms are accompanied by fitted theoretical income distributions assumed as the Burr-type III model (also known as the Dagum distribution). The coefficients of distribution similarity (see Jędrzejczak, 2015b), taking value from the interval $\langle 0,1\rangle$, confirm the satisfactory goodness-of-fit for both countries.

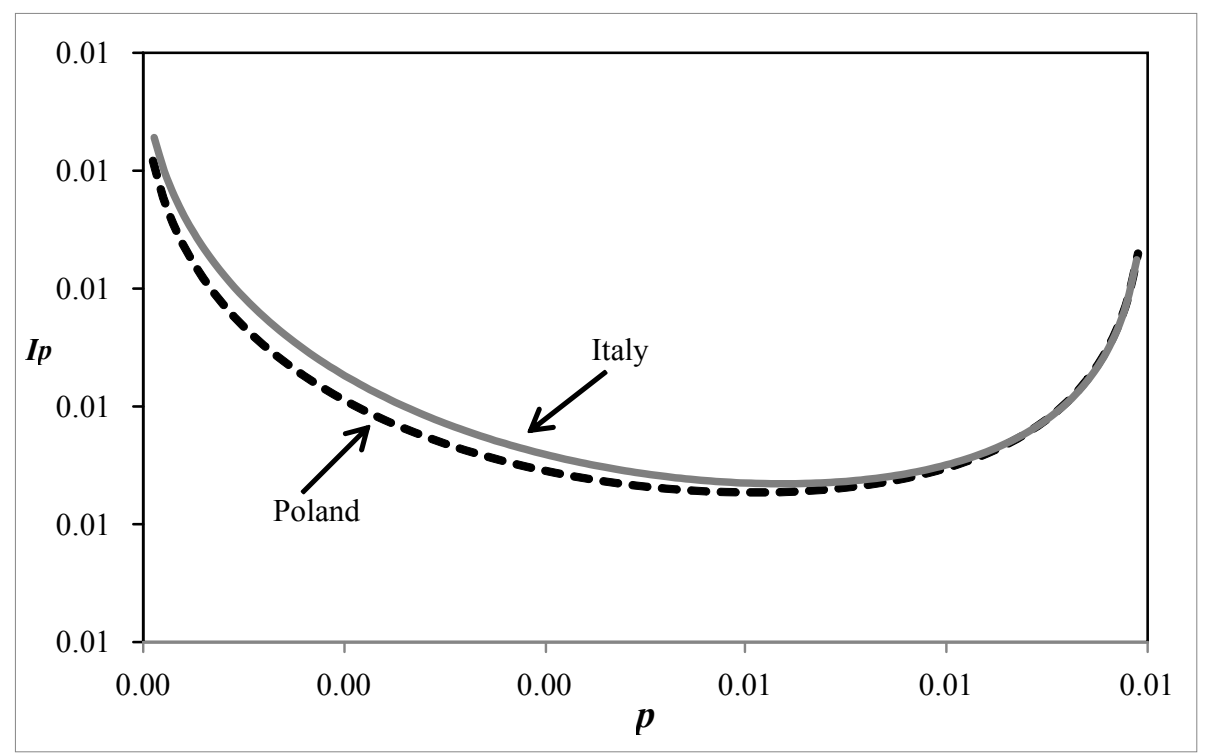

Fig. 2. Zenga inequality curves $I_{p}(Y)$ for Poland and Italy

Source: authors' elaboration.

Figure 2 depicts the graphical representation of point inequality given by formula (1) for all values of $p \in\langle 0 ; 1\rangle$. One can observe only slight discrepancies between the curves, which diminish for high income groups. This is confirmed by similar synthetic Zenga indexes estimated for Poland and Italy: $Z(Y)_{\text {Poland }}=0.69, Z(Y)_{\text {Italy }}=0.70$, which can be interpreted as the areas under the curves up to the line $y=0$. One can also conclude that, on average, the "poorest" households in both countries have mean incomes equal to about $30 \%$ of the mean incomes of the more affluent ones. It is also worth noting that the popular Gini indexes evaluated for both countries are close enough $\left(G_{\text {Poland }}=0.34\right.$ and $G_{\text {Italy }}=0.35$ ). To reveal hidden differences between income distributions in Poland and Italy the authors decompose inequality. 
Decompositions by macroregion of the point $I_{h}(Y)$ and synthetic $I(Y)$ indexes for both countries are presented in Tables 3 to 10, while in Tables 11 and 12 one can find the decompositions by income sources of the synthetic $I(Y)$ and selected point indexes: $I_{h(0.1)}(Y), I_{h(0.5)}(Y), I_{h(0.95)}(Y)$. The positions of point indexes (i.e. orders of distribution quantiles) equal to $p=0.1, p=0.5$ and $p=0.95$ were chosen to reflect the most important characteristics of income distributions, making it possible to compare the poorest, intermediate and the richest groups of households. In particular, the point index for $p=0.1$ compares the mean income of the poorest $10 \%$ households with the mean income of the remaining $90 \%$ households. The point index for $p=0.5$, corresponding to the position of median income, compares two halves of the populations of income receivers: the poorer and the richer $50 \%$ of households. The point index calculated at the quantile of order $p=0.95$ is of particular importance as it enables comparing the "poorest" $95 \%$ of households with the richest $5 \%$.

The differences among the contributions of Italian macroregions (Tables 7 to 10$)$ to the overall inequality are remarkable compared to the Polish case (Tables 3 to 6). In Italy the highest contribution is due to the poorest region 3 (South) being 0.3232, while in Poland the situation is inversed: the most affluent region 1 (Central) plays the most important role in the constitution of income inequality with the contribution equal to 0.1478 . In fact, it is the poorest region in Italy, and the wealthiest in Poland, that represent the

Table 3

Decomposition by macroregion of $I(Y)=0.6899$ based on the Polish HBS 2014

\begin{tabular}{|c|c|c|c|c|c|c|c|}
\hline \multicolumn{7}{|c|}{$B_{. l g} Y$} & \multirow{9}{*}{ Poland } \\
\hline Macroregion & \multicolumn{6}{|c|}{$l$} & \\
\hline$g$ & Central & South & East & N-West & S-West & North & \\
\hline Central & 0.0438 & 0.0398 & 0.0374 & 0.0305 & 0.0220 & 0.0323 & \\
\hline South & 0.0261 & 0.0229 & 0.0224 & 0.0177 & 0.0129 & 0.0192 & \\
\hline East & 0.0211 & 0.0186 & 0.0180 & 0.0144 & 0.0104 & 0.0155 & \\
\hline N-West & 0.0231 & 0.0205 & 0.0198 & 0.0158 & 0.0115 & 0.0170 & \\
\hline S-West & 0.0136 & 0.0119 & 0.0116 & 0.0092 & 0.0067 & 0.0100 & \\
\hline North & 0.0202 & 0.0179 & 0.0172 & 0.0138 & 0.0100 & 0.0148 & \\
\hline \multicolumn{8}{|c|}{ Zenga index decomposition } \\
\hline Total inequality & 0.1478 & 0.1316 & 0.1266 & 0.1015 & 0.0736 & 0.1088 & 0.6899 \\
\hline Within groups & 0.0438 & 0.0229 & 0.0180 & 0.0158 & 0.0067 & 0.0148 & 0.1221 \\
\hline Between groups & 0.1040 & 0.1087 & 0.1086 & 0.0857 & 0.0668 & 0.0940 & 0.5678 \\
\hline
\end{tabular}

Source: authors' calculations. 
Table 4

Decomposition by macroregion of $I_{h(0.10)}(Y)=0.7612$ based on the Polish HBS 2014

\begin{tabular}{|c|c|c|c|c|c|c|c|}
\hline \multicolumn{7}{|c|}{$B_{h l g} Y(h=2251, p=0.1)$} & \multirow{9}{*}{ Poland } \\
\hline Macroregion & \multicolumn{6}{|c|}{$l$} & \\
\hline$g$ & Central & South & East & N-West & S-West & North & \\
\hline Central & 0.0426 & 0.0343 & 0.0416 & 0.0275 & 0.0195 & 0.0319 & \\
\hline South & 0.0322 & 0.0257 & 0.0313 & 0.0206 & 0.0147 & 0.0240 & \\
\hline East & 0.0244 & 0.0195 & 0.0237 & 0.0156 & 0.0111 & 0.0182 & \\
\hline N-West & 0.0262 & 0.0210 & 0.0255 & 0.0168 & 0.0119 & 0.0195 & \\
\hline S-West & 0.0163 & 0.0130 & 0.0158 & 0.0104 & 0.0074 & 0.0122 & \\
\hline North & 0.0231 & 0.0185 & 0.0225 & 0.0148 & 0.0105 & 0.0172 & \\
\hline \multicolumn{8}{|c|}{ Zenga point index decomposition $p=0.1$} \\
\hline Total inequality & 0.1647 & 0.1320 & 0.1603 & 0.1059 & 0.0752 & 0.1230 & 0.7612 \\
\hline Within groups & 0.0426 & 0.0257 & 0.0237 & 0.0168 & 0.0074 & 0.0172 & 0.1335 \\
\hline Between groups & 0.1221 & 0.1063 & 0.1366 & 0.0891 & 0.0678 & 0.1058 & $\mathbf{0 . 6 2 7 7}$ \\
\hline
\end{tabular}

Source: authors' calculations.

Table 5

Decomposition by macroregion of $I_{h(0.50)}(Y)=0.6435$ based on the Polish HBS 2014

\begin{tabular}{|c|c|c|c|c|c|c|c|}
\hline \multicolumn{7}{|c|}{$B_{h l g} Y(h=9872, p=0.5)$} & \multirow{9}{*}{ Poland } \\
\hline Macroregion & \multicolumn{6}{|c|}{$l$} & \\
\hline$g$ & Central & South & East & N-West & S-West & North & \\
\hline Central & 0.0368 & 0.0355 & 0.0327 & 0.0274 & 0.0200 & 0.0283 & \\
\hline South & 0.0246 & 0.0236 & 0.0219 & 0.0182 & 0.0133 & 0.0189 & \\
\hline East & 0.0187 & 0.0180 & 0.0166 & 0.0139 & 0.0102 & 0.0144 & \\
\hline N-West & 0.0208 & 0.0200 & 0.0185 & 0.0154 & 0.0113 & 0.0160 & \\
\hline S-West & 0.0124 & 0.0119 & 0.0110 & 0.0092 & 0.0067 & 0.0096 & \\
\hline North & 0.0179 & 0.0172 & 0.0159 & 0.0133 & 0.0097 & 0.0138 & \\
\hline \multicolumn{8}{|c|}{ Zenga point index decomposition $p=0.5$} \\
\hline Total inequality & 0.1312 & 0.1261 & 0.1166 & 0.0974 & 0.0712 & 0.1010 & 0.6435 \\
\hline Within groups & 0.0368 & 0.0236 & 0.0166 & 0.0154 & 0.0067 & 0.0138 & 0.1129 \\
\hline Between groups & 0.0944 & 0.1025 & 0.1000 & 0.0820 & 0.0645 & 0.0872 & 0.5306 \\
\hline
\end{tabular}

Source: authors'calculations. 
Table 6

Decomposition by microregion of $I_{h(0.95)}(Y)=0.7225$ based on the Polish HBS 2014

\begin{tabular}{|c|c|c|c|c|c|c|c|}
\hline \multicolumn{7}{|c|}{$B_{h l g} Y(h=19038, p=0.95)$} & \multirow{9}{*}{ Poland } \\
\hline Macroregion & \multicolumn{6}{|c|}{$l$} & \\
\hline$g$ & Central & South & East & N-West & S-West & North & \\
\hline Central & 0.0603 & 0.0597 & 0.0484 & 0.0448 & 0.0312 & 0.0434 & \\
\hline South & 0.0190 & 0.0188 & 0.0154 & 0.0141 & 0.0099 & 0.0137 & \\
\hline East & 0.0201 & 0.0199 & 0.0162 & 0.0150 & 0.0104 & 0.0145 & \\
\hline N-West & 0.0216 & 0.0215 & 0.0175 & 0.0161 & 0.0112 & 0.0156 & \\
\hline S-West & 0.0108 & 0.0107 & 0.0087 & 0.0081 & 0.0056 & 0.0078 & \\
\hline North & 0.0194 & 0.0192 & 0.0156 & 0.0144 & 0.0100 & 0.0140 & \\
\hline
\end{tabular}

Zenga point index decomposition $p=0.95$

\begin{tabular}{l|l|l|l|l|l|l|l}
\hline Total inequality & 0.1511 & 0.1498 & 0.1218 & 0.1125 & 0.0783 & 0.1090 & $\mathbf{0 . 7 2 2 5}$ \\
\hline Within groups & 0.0603 & 0.0188 & 0.0162 & 0.0161 & 0.0056 & 0.0140 & $\mathbf{0 . 1 3 1 0}$ \\
\hline Between groups & 0.0908 & 0.1310 & 0.1056 & 0.0964 & 0.0727 & 0.0950 & $\mathbf{0 . 5 9 1 5}$ \\
\hline
\end{tabular}

Source: authors' calculations.

Table 7

Decomposition by macroregion of $I(Y)=0.7000$ based on Banca d'Italia sample survey SHIW 2014

\begin{tabular}{l|c|c|c|}
\hline \multicolumn{3}{c|}{$B_{. l g} Y$} \\
\cline { 1 - 3 } \multicolumn{1}{c|}{ Macroregion } & \multicolumn{2}{c}{$L$} \\
\cline { 1 - 3 } \multicolumn{1}{c|}{$g$} & North & Center & South \\
\cline { 1 - 3 } North & 0.1495 & 0.0714 & 0.1872 \\
\cline { 1 - 2 } Center & 0.0561 & 0.0269 & 0.0718 \\
\hline South & 0.0491 & 0.0238 & 0.0642 \\
\hline
\end{tabular}

Zenga index decomposition

\begin{tabular}{l|l|l|l|l}
\hline Total inequality & 0.2547 & 0.1221 & 0.3232 & $\mathbf{0 . 7 0 0 0}$ \\
\hline Within groups & 0.1495 & 0.0269 & 0.0642 & $\mathbf{0 . 2 4 0 6}$ \\
\hline Between groups & 0.1052 & 0.0952 & 0.2589 & $\mathbf{0 . 4 5 9 4}$ \\
\hline
\end{tabular}

Source: authors' calculations. 
Table 8

Decomposition by macroregion of $I_{h(0.1)}(Y)=0.8035$ based on Banca d'Italia sample survey SHIW 2014

\begin{tabular}{|c|c|c|c|c|}
\hline \multicolumn{4}{|c|}{$B_{h l g} Y \quad(h=440, p=0.1)$} & \multirow{6}{*}{ Italy } \\
\hline Macroregion & \multicolumn{3}{|c|}{$l$} & \\
\hline$g$ & North & Center & South & \\
\hline North & 0.1209 & 0.0778 & 0.2441 & \\
\hline Center & 0.0481 & 0.0309 & 0.0971 & \\
\hline South & 0.0506 & 0.0324 & 0.1016 & \\
\hline \multicolumn{5}{|c|}{ Zenga point index decomposition } \\
\hline Total inequality & 0.2196 & 0.1412 & 0.4428 & 0.8035 \\
\hline Within groups & 0.1209 & 0.0310 & 0.1016 & 0.2534 \\
\hline Between groups & 0.0987 & 0.1102 & 0.3412 & 0.5501 \\
\hline
\end{tabular}

Source: authors' calculations.

Table 9

Decomposition by macroregion of $I_{h(0.5)}(Y)=0.6498$ based on Banca d'Italia sample survey SHIW 2014

\begin{tabular}{|c|c|c|c|c|}
\hline \multicolumn{4}{|c|}{$B_{h l g} Y(h=3262, p=0.5)$} & \multirow{6}{*}{ Italy } \\
\hline Macroregion & \multicolumn{3}{|c|}{$l$} & \\
\hline$g$ & North & Center & South & \\
\hline North & 0.1421 & 0.0653 & 0.1728 & \\
\hline Center & 0.0554 & 0.0255 & 0.0676 & \\
\hline South & 0.0450 & 0.0208 & 0.0553 & \\
\hline \multicolumn{5}{|c|}{ Zenga point index decomposition } \\
\hline Total inequality & 0.2425 & 0.1116 & 0.2957 & 0.6498 \\
\hline Within groups & 0.1421 & 0.0255 & 0.0553 & 0.2229 \\
\hline Between groups & 0.1004 & 0.0861 & 0.2404 & 0.4269 \\
\hline
\end{tabular}

Source: authors' calculations. 
Table 10

Decomposition by macroregion of $I_{h(0.95)}(Y)=0.7071$ based on Banca d'Italia sample survey SHIW 2014

\begin{tabular}{|c|c|c|c|c|}
\hline \multicolumn{4}{|c|}{$B_{h l g} Y \quad(h=6945, p=0.95)$} & \multirow{6}{*}{ Italy } \\
\hline Macroregion & \multicolumn{3}{|c|}{$l$} & \\
\hline$g$ & North & Center & South & \\
\hline North & 0.1972 & 0.0856 & 0.1593 & \\
\hline Center & 0.0637 & 0.0277 & 0.0523 & \\
\hline South & 0.0556 & 0.0241 & 0.0446 & \\
\hline \multicolumn{5}{|c|}{ Zenga point index decomposition } \\
\hline Total inequality & 0.3165 & 0.1375 & 0.2562 & 0.7101 \\
\hline Within groups & 0.1972 & 0.0277 & 0.0446 & 0.2695 \\
\hline Between groups & 0.1193 & 0.1097 & 0.2116 & 0.4406 \\
\hline
\end{tabular}

Source: authors' calculations.

highest inequality levels: the Zenga index for the Central region in Poland is $I(Y)=0.7268$ and for South in Italy $I(Y)=0.7122$. Additionally, the South of Italy has a very high contribution to the between-group part of income inequality (0.2589) as its income distribution is "far away" from the remaining more wealthy regions (Table 7). This regularity becomes even more evident for the poorest income groups determined by $p=0.1$ (Table 8), where the contribution of the South to the between-group inequality is 0.3412 , which is $62 \%$ of total between-region inequality in Italy. This result seems really huge, taking into consideration the visibly smaller share of this region in both: the population (27\%) and in the total income in Italy (24\%) (see Table 1). Inversed relationships between the means and regional inequalities that were revealed for both countries confirm the previous findings reported by Jędrzejczak (2015a), where the correlation between the poverty rate and the Gini index by provinces (NUTS2) turned out to be large and positive in Italy and slightly negative in Poland.

In both countries the contributions of particular subpopulations to the overall inequality are determined mainly by their sizes and mean income levels (see also Tables 1 and 2), less by the relative variations of their lower means with respect to the upper mean of the whole population. As a consequence, the within-group inequalities in Poland and Italy are dominated by the wealthiest regions - in Poland: region 1 (Central), in Italy: region 1 (North) - but in Italy this share is as large as $62 \%$ and the remaining two regions have much smaller inputs. In general the contribution of inner 
inequality in Italy is twice as high as in Poland. The within-group inequality can be considered a system characteristic of the economy in a country as it measures directly the differences between the population members rather than the differences between the levels of regional development, which can be connected more with geographical or historical determinants. In both countries the overall Zenga index is dominated by between-group variability, so social policy focused on the reduction of regional differences can significantly reduce total income inequality.

Table 11

Decomposition by sources of the point indexes $I_{h l}(Y)$ and $I_{h}(Y)$ and synthetic indexes $I_{l l}(Y)$ and $I(Y)$ based on the Polish HBS 2014

\begin{tabular}{|r|c|c|c|c|c|c|c|c}
\hline \multirow{2}{*}{ Source } & \multicolumn{2}{|c|}{ Center } & \multicolumn{2}{c|}{ South } & \multicolumn{2}{c|}{ East } & \multicolumn{2}{c}{ Poland } \\
\cline { 2 - 9 } & $B_{. I}()$. & $\beta_{. I}()$. & $B_{.2}()$. & $\beta_{.2}()$. & $B_{.3}()$. & $\beta_{.3}()$. & $\boldsymbol{B}()$. & $\boldsymbol{\beta ( . )}$ \\
\hline
\end{tabular}

Zenga index decomposition

\begin{tabular}{c|c|c|c|c|c|c|c|c}
\hline $\mathrm{X} 1$ & 0.5162 & 0.7102 & 0.4903 & 0.7572 & 0.4146 & 0.5971 & $\mathbf{0 . 4 7 4 7}$ & $\mathbf{0 . 6 8 8 1}$ \\
\hline $\mathrm{X} 2$ & 0.0309 & 0.0425 & 0.0554 & 0.0856 & 0.0663 & 0.0955 & $\mathbf{0 . 0 4 8 9}$ & $\mathbf{0 . 0 7 0 9}$ \\
\hline $\mathrm{X} 3$ & 0.1721 & 0.2368 & 0.0982 & 0.1517 & 0.2119 & 0.3052 & $\mathbf{0 . 1 6 2 0}$ & $\mathbf{0 . 2 3 4 8}$ \\
\hline $\mathrm{X} 4$ & 0.0075 & 0.0103 & 0.0034 & 0.0053 & 0.0016 & 0.0023 & $\mathbf{0 . 0 0 4 3}$ & $\mathbf{0 . 0 0 6 2}$ \\
\hline$I_{.}(Y)$ & 0.7268 & 1.00 & 0.6475 & 1.00 & 0.6944 & 1.00 & $\mathbf{0 . 6 8 9 9}$ & $\mathbf{1 . 0 0}$ \\
\hline \multicolumn{6}{|c|}{ Zenga point index decomposition $p=0.10 ; h=2251(\mathrm{Y} \leq 1345.00)$} \\
\hline
\end{tabular}

\begin{tabular}{c|c|c|c|c|c|c|c|c}
\hline $\mathrm{X} 1$ & 0.4042 & 0.5918 & 0.5104 & 0.6937 & 0.4382 & 0.5905 & $\mathbf{0 . 5 1 4 3}$ & $\mathbf{0 . 6 7 5 4}$ \\
\hline $\mathrm{X} 2$ & 0.1276 & 0.1868 & 0.1345 & 0.1828 & 0.1230 & 0.1657 & $\mathbf{0 . 1 1 4 2}$ & $\mathbf{0 . 1 5 0 0}$ \\
\hline $\mathrm{X} 3$ & 0.1459 & 0.2136 & 0.0888 & 0.1207 & 0.1794 & 0.2417 & $\mathbf{0 . 1 2 9 8}$ & $\mathbf{0 . 1 7 0 5}$ \\
\hline $\mathrm{X} 4$ & 0.0053 & 0.0078 & 0.0021 & 0.0029 & 0.0015 & 0.0020 & $\mathbf{0 . 0 0 3 2}$ & $\mathbf{0 . 0 0 4 2}$ \\
\hline$I_{h l}(Y)$ & 0.6830 & 1.00 & 0.7358 & 1.00 & 0.7421 & 1.00 & $\mathbf{0 . 7 6 1 5}$ & $\mathbf{1 . 0 0}$ \\
\hline
\end{tabular}

Zenga point index decomposition $p=0.50 ; h=9872(\mathrm{Y} \leq 3151.00)$

\begin{tabular}{c|c|c|c|c|c|c|c|c}
\hline $\mathrm{X} 1$ & 0.5008 & 0.7414 & 0.4738 & 0.7968 & 0.4136 & 0.6482 & $\mathbf{0 . 4 7 6 1}$ & $\mathbf{0 . 7 3 9 9}$ \\
\hline $\mathrm{X} 2$ & 0.0157 & 0.0232 & 0.0359 & 0.0604 & 0.0335 & 0.0525 & $\mathbf{0 . 0 2 7 0}$ & $\mathbf{0 . 0 4 2 0}$ \\
\hline $\mathrm{X} 3$ & 0.1527 & 0.2261 & 0.0823 & 0.1384 & 0.1895 & 0.2970 & $\mathbf{0 . 1 3 6 7}$ & $\mathbf{0 . 2 1 2 4}$ \\
\hline $\mathrm{X} 4$ & 0.0063 & 0.0093 & 0.0026 & 0.0044 & 0.0015 & 0.0024 & $\mathbf{0 . 0 0 3 7}$ & $\mathbf{0 . 0 0 5 7}$ \\
\hline$I_{h l}(Y)$ & 0.6755 & 1.00 & 0.5946 & 1.00 & 0.6381 & 1.00 & $\mathbf{0 . 6 4 3 5}$ & $\mathbf{1 . 0 0}$ \\
\hline
\end{tabular}

Zenga point index decomposition $p=0.95 ; h=19038(\mathrm{Y} \leq 8143.05)$

\begin{tabular}{c|c|c|c|c|c|c|c|c}
\hline $\mathrm{X} 1$ & 0.4723 & 0.6481 & 0.6834 & 0.7616 & 0.2644 & 0.3497 & $\mathbf{0 . 4 2 5 6}$ & $\mathbf{0 . 5 8 9 1}$ \\
\hline $\mathrm{X} 2$ & 0.0037 & 0.0051 & 0.0111 & 0.0124 & 0.0287 & 0.0380 & $\mathbf{0 . 0 1 6 5}$ & $\mathbf{0 . 0 2 2 8}$ \\
\hline $\mathrm{X} 3$ & 0.2414 & 0.3313 & 0.1953 & 0.2177 & 0.4623 & 0.6115 & $\mathbf{0 . 2 7 2 7}$ & $\mathbf{0 . 3 7 7 4}$ \\
\hline $\mathrm{X} 4$ & 0.0112 & 0.0154 & 0.0075 & 0.0084 & 0.0006 & 0.0008 & $\mathbf{0 . 0 0 7 7}$ & $\mathbf{0 . 0 1 0 7}$ \\
\hline$I_{h l}(Y)$ & 0.7287 & 1.00 & 0.8973 & 1.00 & 0.7560 & 1.00 & $\mathbf{0 . 7 2 2 5}$ & $\mathbf{1 . 0 0}$ \\
\hline
\end{tabular}

Source: authors' calculations. 
Tables 11 and 12 show the results of source decomposition of income inequality in Poland and Italy. Four basic income components (X1 - payroll income, $\mathrm{X} 2$ - pensions and net transfers, $\mathrm{X} 3$ - net self-employment income, $\mathrm{X} 4$ - property incomes) were taken into consideration. As the regional division was not the main point here, in Table 11 only the selected regions are presented.

Table 12

Decomposition by sources of the point indexes $I_{h l}(Y)$ and $I_{h}(Y)$ and synthetic indexes $I_{l}(Y)$ and $I(Y)$ based on Banca d'Italia sample survey SHIW 2014

\begin{tabular}{|c|c|c|c|c|c|c|c|c}
\hline \multirow{2}{*}{ Source } & \multicolumn{2}{|c|}{ Nogion } & \multicolumn{2}{c|}{ Center } & \multicolumn{2}{c|}{ South } & \multicolumn{2}{c}{ Italy } \\
\cline { 2 - 9 } & $B_{. I}()$. & $\beta_{. I}()$. & $B_{.2}()$. & $\beta_{.2}()$. & $B_{.3}()$. & $\beta_{.3}()$. & $\boldsymbol{B}()$. & $\boldsymbol{\beta}()$. \\
\hline
\end{tabular}

Zenga index decomposition

\begin{tabular}{c|c|c|c|c|c|c|c|c}
\hline $\mathrm{X} 1$ & 0.2713 & 0.4030 & 0.2544 & 0.3756 & 0.3435 & 0.4823 & $\mathbf{0 . 2 9 4 3}$ & $\mathbf{0 . 4 2 0 5}$ \\
\hline $\mathrm{X} 2$ & 0.1015 & 0.1508 & 0.1675 & 0.2473 & 0.1239 & 0.1739 & $\mathbf{0 . 1 2 2 8}$ & $\mathbf{0 . 1 7 5 4}$ \\
\hline $\mathrm{X} 3$ & 0.1455 & 0.2161 & 0.1094 & 0.1616 & 0.1397 & 0.1961 & $\mathbf{0 . 1 3 7 9}$ & $\mathbf{0 . 1 9 7 0}$ \\
\hline $\mathrm{X} 4$ & 0.1549 & 0.2300 & 0.1459 & 0.2154 & 0.1052 & 0.1477 & $\mathbf{0 . 1 4 5 0}$ & $\mathbf{0 . 2 0 7 1}$ \\
\hline$I_{l}(Y)$ & 0.6732 & 1.00 & 0.6773 & 1.00 & 0.7122 & 1.00 & $\mathbf{0 . 7 0 0 0}$ & $\mathbf{1 . 0 0}$ \\
\hline
\end{tabular}

Zenga point index decomposition $p=0.10 ; h=440(Y \leq 10400.00)$

\begin{tabular}{c|c|c|c|c|c|c|c|c}
\hline $\mathrm{X} 1$ & 0.3522 & 0.4256 & 0.2950 & 0.3630 & 0.3575 & 0.4740 & $\mathbf{0 . 3 4 9 4}$ & $\mathbf{0 . 4 3 4 8}$ \\
\hline $\mathrm{X} 2$ & 0.1826 & 0.2207 & 0.2503 & 0.3080 & 0.1788 & 0.2371 & $\mathbf{0 . 1 8 9 3}$ & $\mathbf{0 . 2 3 5 6}$ \\
\hline $\mathrm{X} 3$ & 0.1136 & 0.1376 & 0.1004 & 0.1235 & 0.1009 & 0.1338 & $\mathbf{0 . 1 0 7 3}$ & $\mathbf{0 . 1 3 3 5}$ \\
\hline $\mathrm{X} 4$ & 0.1790 & 0.2164 & 0.1670 & 0.2055 & 0.1170 & 0.1551 & $\mathbf{0 . 1 5 7 6}$ & $\mathbf{0 . 1 9 6 1}$ \\
\hline$I_{h l}(Y)$ & 0.8274 & 1.00 & 0.8127 & 1.00 & 0.6542 & 1.00 & $\mathbf{0 . 8 0 3 5}$ & $\mathbf{1 . 0 0}$ \\
\hline
\end{tabular}

Zenga point index decomposition $p=0.50 ; h=3262(Y \leq 25107.88)$

\begin{tabular}{c|c|c|c|c|c|c|c|c}
\hline $\mathrm{X} 1$ & 0.2694 & 0.4235 & 0.2619 & 0.4080 & 0.3420 & 0.5275 & $\mathbf{0 . 2 9 0 9}$ & $\mathbf{0 . 4 4 7 7}$ \\
\hline $\mathrm{X} 2$ & 0.1055 & 0.1659 & 0.1586 & 0.2476 & 0.0838 & 0.1292 & $\mathbf{0 . 1 1 1 7}$ & $\mathbf{0 . 1 7 1 9}$ \\
\hline $\mathrm{X} 3$ & 0.1187 & 0.1866 & 0.0864 & 0.1347 & 0.1243 & 0.1917 & $\mathbf{0 . 1 1 2 6}$ & $\mathbf{0 . 1 7 3 3}$ \\
\hline $\mathrm{X} 4$ & 0.1425 & 0.2240 & 0.1346 & 0.2097 & 0.0983 & 0.1516 & $\mathbf{0 . 1 3 4 6}$ & $\mathbf{0 . 2 0 7 1}$ \\
\hline$I_{h l}(Y)$ & 0.6362 & 1.00 & 0.6418 & 1.00 & 0.6483 & 1.00 & $\mathbf{0 . 6 4 9 8}$ & $\mathbf{1 . 0 0}$ \\
\hline
\end{tabular}

Zenga point index decomposition $p=0.95 ; h=6945(Y \leq 67436.07)$

\begin{tabular}{c|c|c|c|c|c|c|c|c}
\hline $\mathrm{X} 1$ & 0.1851 & 0.2715 & 0.1685 & 0.2550 & 0.2348 & 0.3002 & $\mathbf{0 . 1 9 7 7}$ & $\mathbf{0 . 2 7 8 4}$ \\
\hline $\mathrm{X} 2$ & 0.0731 & 0.1072 & 0.1498 & 0.2264 & 0.0748 & 0.0956 & $\mathbf{0 . 0 9 1 7}$ & $\mathbf{0 . 1 2 9 1}$ \\
\hline $\mathrm{X} 3$ & 0.2462 & 0.3611 & 0.1868 & 0.2826 & 0.3439 & 0.4396 & $\mathbf{0 . 2 5 2 1}$ & $\mathbf{0 . 3 5 5 0}$ \\
\hline $\mathrm{X} 4$ & 0.1774 & 0.2602 & 0.1560 & 0.2360 & 0.1288 & 0.1646 & $\mathbf{0 . 1 6 8 6}$ & $\mathbf{0 . 2 3 7 4}$ \\
\hline$I_{h l}(Y)$ & 0.6818 & 1.00 & 0.6610 & 1.00 & 0.7822 & 1.00 & $\mathbf{0 . 7 1 0 1}$ & $\mathbf{1 . 0 0}$ \\
\hline
\end{tabular}

Source: authors' calculations. 
Analysing the results of the calculations presented in Tables 11 and 12 , one can easily notice that payroll income (X1) is the income source having the biggest influence on income inequality in both countries, however its contribution to the overall inequality was much higher in Poland and equalled $68.81 \%$, (Italy $-42.05 \%$ ). It is worth noting that the share of property incomes $\mathrm{X} 4$, the second biggest in Italy $-20.71 \%$, is quite negligible in Poland $-0.62 \%$. In both countries this component's share increases for more affluent regions (North in Italy and Central in Poland).

The contribution of pensions and net transfers (X2), constituting about $30 \%$ of household income in both countries (see Tables 1 and 2), remains relatively small in Poland with a share of only $7 \%$ in the overall income inequality. Such a result was possible because of the very small inner dispersion of pensions in Poland, i.e. the small relative variations of the lower means of this component with respect to the upper mean of the total income. The corresponding share of pensions and net transfers in Italy was much higher and equalled $17.54 \%$. For $p=0.1$ one can observe substantial changes in X2 shares for both countries: for Poland it doubled from $7.09 \%$ to $15 \%$, while in Italy it rose from $17.54 \%$ to $23.56 \%$. An interesting result may also be noticed, in favour of the income distribution in Poland, which consists in a significant share of income from self-employment (X3) in both total income received by the households (13\%) and its inequality $(23.48 \%)$. The corresponding results for Italy are $10 \%$ and $19.7 \%$, respectively. The economic activity of the Polish households is even higher in the relatively poor Southern region with an income share of $16 \%$ and inequality share of $30.52 \%$.

It was also interesting to find out that the source decomposition of income inequality for the richest households in Poland (bottom of Table 11), corresponding to the point inequality index $I_{0.95}(Y)$ becomes more similar to the decomposition of the overall Zenga index $I(Y)$ in Italy (top of Table 12). It can be interpreted that the upper part of income distribution in Poland slowly converges with the income distribution pattern observed for Italy, which is particularly expressed in the higher contribution of property income and smaller contribution of payroll income to total inequality. Moreover, the contributions of income from self-employment observed for the richest income groups $(p=0.95$ ) are similar in both countries - in Poland $37.74 \%$, in Italy $35.5 \%$, while the extremely high contribution of this income source for the richest households was observed in the South of Poland, where it was as high as $61.15 \%$. 


\section{CONCLUSION}

In this paper, the decompositions by subpopulations as well as by income components of the point $I_{h}(Y)$ and the synthetic $I(Y)$ inequality indexes proposed by Zenga (2007) were considered, and also the decomposition into within and between-group inequality was carried out. In contrast to the two-step decomposition by subpopulations of the Gini index which may yield negative contributions, for Zenga index, by construction, this situation cannot happen. The comparative analysis, which was based on the micro data on household incomes obtained for both countries, helped to reveal several differences in inequality patterns in Poland and Italy, although the countries present similar inequality levels measured by the Gini and Zenga indexes. The differences are especially remarkable when analysing source decomposition: the negligible share of property income in average income in Poland (in total and for regions), accompanied by very small shares of property income and pensions in the overall inequality, helped to recognise income distribution which still can be considered the heritage of a centrally planned economy. The group decomposition conducted for macroregions also revealed some differences, among them the inversed relationship between the economic levels of regions and their contributions to overall inequality. In both countries the overall income inequality is dominated by the variability between macroregions therefore a social policy focused on the reduction of regional differences can significantly reduce this phenomenon. The detailed results obtained within the study suggest that inequality decomposition based on the Zenga approach can be helpful for better understanding of the issue of income distribution and income inequality and can be used in many further economic analyses, including poverty and social welfare investigations where the estimates of inequality components can be applied.

\section{REFERENCES}

Arcagni, A., Porro, F. The Graphical Representation of Inequality, "Revista Colombiana de Estadistica", 37, 2, pp. 419-437, 2014.

Arcagni, A., Zenga, M., The decompositions by sources of $\zeta$ inequality index, Proceeding of the 47th Scientific Meeting of the Italian Statistical Society, Cagliari, 2014.

Arcagni, A., On the decompositions by sources of the Zenga 1984 point and synthetic inequality indexes, "Statistical Methods and Applications", 26, 1, pp. 113-133, 2017.

Bank of Italy, Household Income and Wealth in 2014, Supplements to the Statistical BulletinSample Survey, 2016. 
Bonferroni, C., Elementi di Statistica Generale. Seeber, Firenze 1930.

Dagum, C., A new approach to the decomposition of the Gini income inequality ratio, "Empirical Economics", 22, 4, pp. 515-531, 1997 .

Dagum, C., Scomposizione ed interpretazione delle misure di diseguaglianza di Gini e di entropia generalizzata, "Statistica", 3, pp. 295-307, 1997 .

Gini, C., Sulla Misura della Concentrazione e della Variabilità dei Caratteri, Atti del Reale Istituto Veneto di Scienze, Lettere ed Arti, Anno Accademico 1913-1914, Tomo LXXIII, Parte Seconda, 1914.

Greselin, F., Pasquazzi, L., Zitikis, R. Zenga's New Index of Economic Inequality, its Estimation, and Analysis of Incomes in Italy, "Journal of Probability and Statistics", ID 718905, pp. 1-26, 2010.

Greselin, F., Pasquazzi, L., Zitikis, R. Contrasting the Gini and Zenga Indices of Economic Inequality, "Journal of Applied Statistics", 40, 2, pp. 282-297, 2013.

Jędrzejczak, A., Decomposition Analysis of Income Inequality in Poland by Subpopulations and Factor Components, "Argumenta Oeconomica", 1, 24, pp. 109-123, 2010.

Jędrzejczak, A., Regional Income Inequalities in Poland and Italy, "Comparative Economic Research", 18, 4, pp. 27-45, $2015 a$.

Jędrzejczak, A., Asymptotic Properties of Some Estimators for Gini and Zenga Inequality Measures:A Simulation Study, "Statistica \& Applicazioni”, 13, pp. 143-162, 2015b,

Langel, M., Tillé, I., Inference by linearization for Zenga's new inequality index: a comparison with the Gini index, "Metrika", 75, 8, pp. 1093-1110, 2012.

Lerman, R., Yitzhaki, S., Income inequality effects by income sources: a new approach and applications to the United States, "The Review of Economics and Statistics", 67, pp. 151156. 1985,

Maffenini, W., Polisicchio, M., The potential of the I(p) inequality curve in the analysis of empirical distributions, "Statistica \& Applicazioni", 12, 1, pp. 63-85, 2014.

Monti, M., A Note on the Residual Term $R$ in the Decomposition of the Gini Index, "Argumenta Oeconomica", 1, 20, pp. 107-138. 2008.

OECD Report, Growing Unequal?, 2008, https:/www.oecd.org/els/soc/41527936.pdf

OECD Report, Divided We Stand. Why Inequality Keeps Rising, 2011, https://www.oecd. org/els/soc/49170768.pdf

OECD Report, In It Together: Why Less Inequality Benefits All, 2015, https://www.oecd. org/els/soc/OECD2015-In-It-Together-Chapter1-Overview-Inequality.pdf

Persson, T., Tabellini, G., Is inequality harmful for growth? "American Economic Review", 84, 3, pp. 600-621, 1994.

Pasquazzi, L., Zenga, M., Components of Gini, Bonferroni and Zenga inequality indexes for EU income data, "Journal of Official Statistics", 34, 1, pp. 1-32, 2018.

Piketty, T., Capital in the Twenty-First Century. Harvard University Press, Cambridge 2014.

Polisicchio, M., The continuous random variable with uniform point inequality measure $I(p)$, "Statistica \& Applicazioni", 6, 2, pp. 137-151, 2008.

Polisicchio, M., Porro, F., A comparison between Lorenz L(p) curve and Zenga I(p) curve, "Statistica applicata", 21, 3-4, pp. 289-301, 2011. 
Porro, F., Zenga, M. The decompositions by subgroups of the inequality curve $Z(p)$ and the inequality index $\zeta$, Proceeding of the 47th Scientific Meeting of the Italian Statistical Society, Cagliari 2014.

Pyatt, G., On the Interpretation and Dissagregation of the Gini Coefficients, "The Economic Journal", 86, 342, pp. 243-255 1976.

Radaelli, P., Zenga, M., On the decomposition of the Gini mean difference and concentration ratio, "Statistica \& Applicazioni", 3, 2, pp. 5-24, 2005.

Radaelli, P., A subgroups decomposition of Zenga's uniformity and inequality indexes, "Statistica \& Applicazioni", 6, 2, pp. 117-136, 2008.

Radaelli, P., On the Decomposition by Subgroups of the Gini Index and Zenga's Uniformity and Inequality Indexes, "International Statistical Review", 78, 1, 81-101, 2010.

Rao, V., Two decompositions of concentration ratio, "Journal of the Royal Statistical Society", Ser. A, 132, pp. 418-425, 1969.

Shorrocks, A., The class of additively decomposable inequality measures, "Econometrica", 48, 3, pp. 613-626, 1980.

Statistics Poland, Household Budgets Survey in 2014. Statistical Information and Elaborations, Warsaw 2015.

Sztaudynger, J., Kumor, P., The Optimal Inequality of Earnings - The Econometric Analysis, "Comparative Economic Research", 1-2, pp. 45-61, 2007.

Tarsitano, A., The Bonferroni index of inequality,[in:] Dagum, C., Zenga, M. (eds.) Income and Wealth Distribution, Inequality and Poverty, pp. 228-242. Springer Verlag, Berlin 1990.

Tárki European Social Report 2009, http://old.tarki.hu/en/research/european_social_report/ european_social_report_2009_full.pdf

Zenga, M., Proposta per un indice di concentrazione basato sui rapport fra quantili di popolazione e quantili di reddito, "Giornale degli economisti e annali di economia", 43, 5-6, pp. 301-326, 1984.

Zenga, M., Concentration Curves and Concentration Indices Derived from Them, [in:] Dagum, C., Zenga, M. (eds.) Income and Wealth Distribution, Inequality and Poverty, pp. 94-110. Springer Verlag, Berlin 1990.

Zenga, M., Inequality curve and inequality index based on the ratios between lower and upper arithmetic means, "Statistica \& Applicazioni”, 5, 1, pp. 3-27, 2007.

Zenga, M., Radaelli, P., Zenga, M., Decomposition of Zenga's inequality index by sources, "Statistica \& Applicazioni”, 9, 1, pp. 3-34, 2012.

Zenga, M., Decomposition by sources of the Gini, Bonferroni and Zenga inequality indexes, "Statistica \& Applicazioni", 11, 2, pp. 133-161, 2013.

Zenga, M., On the decomposition by subpopulations of the point and synthetic Zenga (2007) inequality indexes, "Metron", 74, 3, pp. 375-405, $2016 a$.

Zenga, M., Valli, I., On the decomposition by subpopulations of the point and synthetic Bonferroni inequality measures, "Statistica \& Applicazioni”, 14, 1, pp. 3-28, 2016.

Zenga, M., Decomposition by subpopulations of the point and synthetic Gini inequality indexes, "Statistica \& Applicazioni”, 14, 1, 49-82, $2016 b$. 